\title{
LA 'AFRENTA DE CORPES' A LA LUZ DE ALGUNOS MOTIVOS LITERARIO-FOLKLÓRICOS CLÁSICOS Y MEDIEVALES
}

Distintos son los motivos de interés que ofrece el episodio de la 'Afrenta de Corpes' en el Poema de mío Cid ${ }^{1}$, ya sea desde el punto de vista histórico, ya sea por los topos literarios, varia y autónomamente reelaborados con personal originalidad por el autor del poema. Hablo de autor, porque sigo aquel filón de la crítica ${ }^{2}$ (distinto del de Menéndez Pidal) que considera la obra no como el producto de dos manos sucesivas, la primera la de un juglar y la segunda la de un hombre de más escuela, sino como la obra unitaria de un solo autor, más bien culto y hasta familiarizado con textos latinos clásicos ${ }^{3}$ y contemporáneos ${ }^{4}$; con no-

1 Ramón Menéndez Pidal, Poema de mio Cid, edición, introducción y notas de Ramón Menéndez Pidal, Espasa-Calpe (Clásicos Castellanos, 24), Madrid, 197113.

2 Jules Horrent, Historia y poesía en torno al "Cantar del Cid», Ariel, Barcelona, 1973, págs. 310 sigs.; Aurelio Roncaglia, sub voce Poema de mío Cid, en «Enciclopedia Europeax, Garzanti, Milano, 1976, tomo 8, págs. 1048-1049; Colin SMITH, Estudios Cidianos, Cupsa, Madrid, 1977, pág. 122; Leo SpITzER, Sobre el caracter historico del Cantar de mio Cid, en «Nueva Revista de Filología Hispánica», Madrid, II, 1948, páginas 104-105; Roger WALKER, A possible source for the 'Afrenta de Corpes' episode in the 'Poema de mio Cid', en *Modern Language Review», LXXII, 1977, pá. 336. Para un compendio acerca del problema de la fecha de la obra cfr. Francisco LoPEz EsTRADA, Poema del Cid, Castalia (Odres Nuevos), Madrid, 19788, pág. XVII.

3 Como ha demostrado Colin SMITH, op. cit., págs. 113 sigs., con las citas y el examen de los trozos de Salustio y de Frontino a los que parecen referirse unos pasajes del Cid. Y si es probable que el Salustio del Bellum Jugurthinum fue conocido por un hombre que había estudiado un poco, a los Stratagemata de Frontino 
ciones de derecho y de jurisprudencia ${ }^{5}$ y buen conocimiento de las obras literarias también en lengua francesa ${ }^{6}$.

Me ocuparé, en primer lugar del problema de la fecha del Cantar, ya que ésta es importante para poner en relación el episodio de la 'Afrenta de Corpes' con los distintos motivos literarios, que es el objetivo principal de este trabajo.

Desde el punto de vista histórico, tenemos muchos estudios ${ }^{7}$ para aclarar la realidad de los personajes que se encuentran en la obra. Se ha visto, en fin, que todos o casi todos se hallan en los documentos de edad contemporánea a la de Poema; las únicas divergencias entre el poema y los documentos son las atribuibles a las licencias o distracciones (?) que el autor se ha concedido: la unificación de los sucesivos destierros del $\mathrm{Cid}^{8}$, el episodio del león (vv. 2278-2310), los nombres de las hijas del Cid que en el Poema resultan doña Elvira y doña Sol, mientras que, en realidad, se llamaban María y Cristina ${ }^{9}$ y la incongruencia al decir en los versos 3273-74: ... señoras son sues fijas de Navarra e de Aragón. / Oy los reyes d'España sos parientes son, cuando se sabe que, a lo sumo, se puede hablar de rey sólo para el marido de Cristina, mientras que la otra, después de haberse casado con el infante don Pedro de Aragón, que no tuvo jamás reino y la dejó viuda y sin hijos, volvió a casarse con el conde de Barcelona ${ }^{10}$. Está, en fin, la presencia continua de Alvar Fáñez al lado del Cid y, en cambio, los documentos dicen que este

se los conoce mucho menos, aunque se trate de una obra que tiene unas características didascálicas muy apreciadas en la Edad Media.

4 Cfr. Silvio Pellegrini, Epica francese e Cantare del Cid, en «Cultura Neolatinaw, III, 1948, págs. 233-36; R. MenéNdez Pidal, op. cit., pág. 35.

5 Louis Chalon, L'histoire et l'épopeé castillane du Moyen Age, Champion, Paris, 1976, págs. 157-173; Colin Smith, op. cit., págs. 57 y 63-86.

6 L. Chalon, op. cit., pág. 149; J. HorRent, op. cit., págs. 341-374; R. MEnÉndez Pidal, op. cit., págs. 32-41; C. SMITH, op. cit., págs. 125-159.

7 L. Chalon, A propos des filles du Cid, en «Le Moyen Age», LXXIII, 1967, páginas 213-237; J. HoRReNT, op. cit., 'Introducción', págs. 7-89; A. Huici Miranda, Historia musulmana de Valencia y su Región, Valencia, 1970; Las luchas del Cid Campeador con los almorávides y el enigma de su hijo Diego, en «Hesperis», VI, 1965, pág. 82; E. LÉvi-Provençal, Islam d'Occident, Paris, 1948; Le Cid de l'histoire, en «Revue Historiquew, 180, 1937, págs. 58-74; R. Ment́ndez PIDAL, Cantar de Mío Cid, texto gramática y vocabulario, Espasa-Calpe, Madrid, 1956-59, págs. 544552; La Chanson de Roland y el neotradicionalismo, Madrid, 1959, págs. 429 y sigs.; La España del Cid, EspasaCalpe, Madrid, 1956; Poema..., págs. 13-23; C. SMIth, op. cit., págs. 35-62; ANTonio UвIETo ARTETA, Observaciones al CMC, en 'Arbor', XXXVII, 1957, págs. 145-170.

8 L. Chalon, L'histoire ..., págs. 1-82; J. HoRrent, op. cit., Introducción, págs. 7-90; R. Menéndez Pidal, Poema..., págs. 14-15, 28; C. Smith, op. cit., págs. 13-62.

9 L. Chalon, A propos..., págs. 213-237; L'histoire..., págs. 2434; J. HoRRENT, op. cit., págs. 284-299; C. SMITH, op. cit., págs. 39-40.

10 L. Chalon, L'histoire..., págs. 28-34, 163-165; J. Horrent, op. cit., pág. 88; R. MENéndez Pidal, Poema..., págs. 14-15. 
caballero, por algún tiempo, mientras que el Campeador aún sufría el destierro, estuvo en la corte del rey Alfonso VI", y el episodio de la Afrenta de Corpes, después del cual los Infantes de Carrión, demandados ante el rey por el Cid, son reconocidos culpables y condenados. Las incongruencias de este último pasaje son más bien grandes: los dos Infantes, si verdaderamente fueron reconocidos culpables por sus imputaciones (alevosía, traición y menos valer), habrían debido ser condenados a muerte y se les hubieran confiscado los bienes de su familia ${ }^{12}$. Pero los documentos originales de la época no tienen ninguna traza ni de discusión ni de juicio ni de condena ${ }^{13}$. Además la enemistad entre su familia, la de Beni-Gómez, y la de Bivar es posterior a la fecha en la cual habían acaecido los hechos ${ }^{14}$. Más aún: parece muy extraño que un poeta que por sus cualidades (aunque no sepamos su nombre), tenía que ser bien conocido y por lo mismo apreciado, se hubiera atrevido, tan pocos años después de la muerte del Cid, cuando la familia Beni-Gómez aún era tan fuerte, a denigrar tan pesada e impunemente a algunos de sus componentes. Última observación: la figura del rey Alfonso VI aparece un poco mezquina, y quizás realistamente pintada (creyó las falsas acusaciones de los enemigos del Cid, renovando su antigua desconfianza hacia él, nacida en los días de su coronación, lo desterró y luego volvió a hacer las paces con él, según parece, empujado por el hecho de que Rodrigo, aunque desterrado, sigue conservando la devoción de un buen vasallo y enviándole su parte de botín, pero, en efecto, sobre todo porque ahora el Campeador con su valor y su inteligencia ha conquistado un reino $y$, aunque sin título, se ha convertido en un verdadero rey en

11 L. Chalon, L'histoire..., págs. 34-36; J. Horrent, op. cit., págs. 276-280; C. SmIth, op. cit., págs. 46-47.

12 L. Chalon, L'histoire..., págs. 157-170; pág. 161: «Pour le Fuero de Cuenca, le personnage reconnu traydor envers son seigneur était exilé de sa ville et sa demeure était rasée. Las Partidas, plus sévères encore, prévoient la condamnation à mort et la confiscation des biens du traydor»; pág. 168: "Dans un duel judiciaire, le vaincu se trouvait devant l'alternative peu rejouissante de reconnaître que son vainqueur avait raison ou d'accepter d'être mis à morte».

13 L. Chalon, L'histoire..., págs. 169-170: «... nous avons déjà insisté sur le fait que, dans le Cantar, les infants - pourtant vaincu et reconnus, du même coup, traidores, alevosos et de menos valer - ne subissent aucune des peines, très lourdes, prévues par tous les fueros pour de tels délits: mise à part la confiscation des armes qu'ils ont utilisées à Carrion (v. 3694), Diego, Fernando et Asur Gonzalez ne font l'objet que d'une condamnation morale (vv. 3705-3707) ... Nous avons vu aussi, ... les conclusions que nous pouvons tirer quant à l'historicité des épisodes du Cantar où appareissent les infants de Carrion, du fait que dans la réalité Diego et Fernando Gonzalez ne furent jamais reconnus comme alevosos, traidores et de menos valer. On ne rappellera qu'entre 1090 et 1105, ils figurent régulièrement dans la schola regis, ce qui serait impensable s'ils avaient été condamnés pour de telles ignominies».

¿4. Chalon, A propos..., pág. 235; L’histoire..., pág. 145. 
las tierras de su conquista); no en vano al principio del Poema el autor dice: "¡Dios, qué buen vasallo, si oviesse buen señor!" (v. 20). ¿Es posible que el autor haya dicho esto y haya tenido parecidos acentos en la misma época en que Alfonso VI reinaba? $\mathrm{Si}$, en cambio, el poema ha sido compuesto en el ambiente de la corte de Alfonso VIII, descendiente del Cid, el hecho se podría aceptar, porque la obra de glorificación del progenitor le da prestigio a él mismo ${ }^{15}$. Según mi parecer, todos estos motivos incitan bastante justificadamente a situar el Poema, como Per Abbat nos lo ha transmitido, en una fecha más reciente que la que nos da Ramón Menéndez Pidal (1140). Me parece mucho más justificada la fecha del 1207 propuesta por varios especialistas ${ }^{16}$, también por otros motivos. La obra ha sido escrita para la glorificación de un hombre que, aunque vivió realmente, ha pasado ya al patrimonio legendario de la historia de un pueblo. Las famosas gestas realmente se han cumplido, pero ya su figura no tiene sólo características y delimitaciones reales, sino también míticas. El Cid muestra su modernidad, incluso al expresar su sentimiento religioso que llena toda su figura, pero que nunca traspasa los justos límites; en él no se da el intolerante espíritu de cruzada, y los combates que sostiene contra los árabes no parecen guiados tanto por un motivo de Reconquista, como por el deseo de conquistarse un territorio y de defender lo que él ya se ha ganado. Enemigos árabes y cristianos se sitúan en el mismo plano. Además Rodrigo mantiene buenas relaciones, alguna vez también de sólida amistad, con personajes árabes. Que en otros tiempos los árabes tuvieran para él, también históricamente, sentimientos de estima y reverencia, lo prueba el título con el que desde entonces todo el mundo lo conoce.

Hay además otro motivo que hace al Cid, a pesar de muchas y justificadas características medievales, especialmente moderno: es la primera figura histórico-mítica medieval de selfmade man. Es verdad que él no era ni un homo novus ni un burgués, pero su nobleza, comparada con la de los Beni-Gómez, era muy inferior; pertenecía a la numerosa clase de los infançones ${ }^{17}$. Tanto más admirable por eso su capacidad de reconquistar, bajo Alfonso VI, la plaza que ya había obtenido, con sus cualidades y su espada, bajo Sancho II, y maravillosa su devoción a la institución real en una época en la que la nobleza europea casi siempre es muy vacilante respecto a la autoridad. Ya se empieza a ver en el Cid, por las

15 L. Chalon, L'histoire..., págs. 144, 209.

16 J. Horrent, op. cit., págs. 252-269; F. LoPez EstradA, op. cit., pág. XVII; R. M. WALKeR, op. cit., pág. 336, nota 5 y pág. 347.

17 L. Chalon, A propos..., pág. 236; L'histoire..., pág. 60. 
propias palabras del héroe, [si] la ventura me fore cumplida (v. 223) ${ }^{18}$, aquel concepto de Fortuna que, a través de un largo camino, finalmente será expresado completamente en el Principe de Niccolò Machiavelli ${ }^{19}$.

Los matices que el autor da a la figura del Cid, el episodio de los judíos, el del león, la ternura del protagonista hacia su familia, el desánimo de los primeros momentos del destierro, su orgullo y su justa ira son todos piezas que ahora, junto con los hechos reales, constituyen el mosaico indivisible del Campeador. Investigar obsesivamente, como han hecho algunos especialistas ${ }^{20}$, la verdad histórica de episodios como el de la caja dejada a Raquel y Vidas (vv. 79-198) o el del león (vv. 2278-2301) me parece un exceso de racionalismo en comparación con una obra que no pretende ser historia versificada, sino la epopeya de un hombre tan grande que llega a ser una leyenda. De ambos sucesos se puede decir que se trata de episodios literariamente típicos: el primero, de hombres que, si bien virtuosos, imprevistamente se encuentran frente a dificultades económicas no superables sino con una estratagema ${ }^{21}$; el segundo forma parte de una tradición literaria muy difundida: ya el monje de San Gallo nos da cuenta de un episodio análogo referido a Pepino el Breve 22. En último término, como modelo de episodios de este tipo, se puede tomar tanto el pasaje del Evangelio que habla de Cristo dormido durante la tempestad, en medio de la angustia de los Apóstoles ${ }^{23}$, como el del Liber pontificalis en el que se narra un suceso parecido ${ }^{24}$; sin tener en cuenta la Berte aus grans piés, que si bien de época posterior al Poema de mio Cid, se basa en un original anterior ${ }^{25}$.

18 UlRICH Leo, La «Afrenta de Corpes» novela psicológica, NRFH, Madrid, XIII, 1959, págs. 291-304; F. LóPEZ EsTRADA, op. cit., pág. LXXXIII.

19 Nrccolo Machiavelli, Il Principe, Introduzione e note di Francesco Chabod. Nuova edizione con aggiornamenti bibliografici a cura di Luigi Firpo, Einaudi (NUE, 4), Torino, 19633, págs. $120-125$.

20 U. Leo, op. cit., págs. 291-304; R. M. WALKER, op. cit., págs. 341-342.

21 L. Chalon, L'histoire..., págs. 198-202; R. Menéndez Pidal, op. cit., págs. 28-30.

22 L. Chalon, L'histoire..., págs. 205-207; U. LBO, op. cit., pág. 297; C. SMith, op. cit., págs. 137-140.

23 Mat., VIII, 23-26; Marc., IV, 36-39; Luc., VIII, 22-25.

24 Liber pontificalis, texte, introduction et commentaire par l'Abbé L. Duchesne, tome premier, E. De Boccard, Paris, 1955, págs. 373-374: Cumque ex omni parte multitudo militiae conveniret, Zacharias spatarius perterritus et trepidans ne a turba militiae occideretur, portas quidem civitatis claudi et teneri pontificem postulabat. Ipse vero in cubiculo pontificis tremebundus refugiit, deprecans lacrimabiliter ut sui pontifex misereretur nec permitteret quemquam eius animae infestari... Dumque fores patriarchii, tam inferiores quamque superiores, essent clausae, et has terra, nisi citius aperirentur, mittere minarentur, prae nimia timoris angustia et vitae disperatione, Zacharias spatarius sub lecto pontificis ingressus sese abscondit, ita ut mente excederet et perderet sensum. (Años 687-701.)

25 L. Chalon, L'histoire..., págs. 205-207; R. Menéndez Pidal, Poema..., pág. 32; C. SмITH, op. cit., pág. 140.

LXIII, $1.0-2.0^{\circ}-6$ 
La fecha de composición del Poema debería ser retrasada también por una serie de datos que el autor no conoce o que -extrañamentese calla: la existencia de un hijo del Cid, Diego, muerto en la batalla de Consuegra en el $1097^{26}$ y la nobleza de doña Jimena, que es por vía directa pariente de Alfonso VI ${ }^{27}$. No me parece justificado que un contemporáneo culto pueda callar noticias semejantes, mientras es más fácil que ya no les dé tanta importancia un hombre que ha vivido aproximadamente un siglo después. Siempre bajo esta óptica se debería ver a los diversos personajes musulmanes que surgen y que, aparte Yuçuf, no parece que hayan existido realmente ${ }^{28}$.

Por lo que se refiere al episodio capital del Cantar de Corpes, recordemos los hechos: los Infantes de Carrión desde siempre descontentos de matrimonios contraídos sólo por interés, se sienten ofendidos por el comportamiento de los cortesanos del Cid, que muy a menudo hacen burla de ellos por la cobardía tantas veces demostrada. Deciden, por eso, vengar su amor propio herido en las inocentes jóvenes esposas. Se despiden del Cid con la disculpa de volver a Carrión para enseñar a sus mujeres sus posesiones. Durante el viaje alejan la escolta y apartándose con sus mujeres las azotan, hasta hacerlas sangrar, con las riendas de los caballos y con sus espuelas y, al final, las dejan medio desnudas y como muertas en el robledo y se van jactándose del hecho. Doña Elvira y doña Sol después son auxiliadas y salvadas.

Las figuras de los Infantes, detalladamente analizadas desde el punto de vista histórico ${ }^{29}$, lo han sido, por desgracia, también desde el psicoanalítico ${ }^{30}$. Si el episodio hubiera sido real, el análisis tendría sentido y podría ser interesante; pero, como se trata de una invención poética, no veo por qué se ha querido hacer patente el complejo de inferioridad derivado de un malentendido sentido del honor que aflige a los Infantes; las componentes sádicas de su comportamiento y en fin su impotencia, dado que, después de dos años de matrimonio, no tienen hijos.

Los dos personajes son ciertamente históricos, muy dudosos son sus matrimonios con las hijas del Cid. En los documentos contemporáneos no hay ningún indicio de matrimonio y además las hijas del Cid están en una edad demasiado infantil para contraer nupcias ${ }^{31}$, mientras que en

26 L. Chalon, L'histoire..., págs. 25-26.

27 L. Chalon, L'histoire..., págs. 22, 81.

28 L. ChaLON, L'histoire..., pág. 82.

29 L. Chalon, L'histoire..., págs. 57-60; J. Horrent, op. cit., págs. 7-90; C. Smith, op. cit., págs. 35-62.

30 U. LEO, op. cit., págs. 291-304; R. M. WALKER, op. cit., págs. 341-347.

31 L. Chalon, L'histoire..., págs. 139-153; J. Horrent, op. cit., págs. 284-311; R. MENéndez Pidal, Poema..., págs. 22-23; C. Smith, op. cit., págs. 39-41. 
el Poema aparecen normales relaciones matrimoniales: Fallaron un vergel con una limpia fuont; / mandan fincar la tienda ifantes de Carrión, / con quantos que ellos traen $i$ yazen essa noch, / con sus mugieres en braços demuéstranles amor; / ... assi lo mandaron ifantes de Carrión, / que non i fincas ninguno, mugier nin varon, / si non amas sus mugieres doña Elvira e doña Sol: / deportar se quieren con ellas a todo su sabor (PMC, vv. 2700-2711, págs. 248-249). El problema podría tener una parcial solución si en lugar de un matrimonio pudiéramos imaginar simplemente esponsales ${ }^{32}$, pero no resolveríamos lo mismo la cuestión de las relaciones entre los personajes, inimaginables sin un vínculo sagrado. Sabemos con certeza las bodas de doña Elvira con el Infante de Navarra, don Ramiro, y las de doña Sol, primero con el Infante de Aragón, don Pedro y, después, con el conde de Barcelona ${ }^{33}$. El odio que empuja a ambos jóvenes a maltratar a las muchachas, en la época en la cual el episodio es descrito, históricamente no tiene razón de ser ${ }^{34}$. Todo el pasaje parece creado por la fantasía del autor por el mero deseo de narrar; en el cuento hay un gran número de topoi literarios característicos de la novela y de las narraciones clásicas.

Los dos hermanos, envidiosos de la riqueza y de la honra familiar de sus esposas, son el equivalente típico de los hermanos o hermanas malos de varios cuentos, desde la Biblia $^{35}$ hasta los autores contemporáneos del poeta. Las dos heroínas, aunque duplicadas, son el correspondiente de héroes y heroínas maltratados: desde José ${ }^{36}$ hasta la Berte aus grans piés ${ }^{37} \mathrm{o}$ la Florence de Rome ${ }^{38}$, donde a la protagonista acaece un suceso parecido al de las hijas del Cid. Los dolores de las muchachas los encontramos en toda novela clásica y también el fausto desarrollo

32 L. Chalon, L'histoire..., págs. 147-152; J. HoRRent, op. cit., págs. 284298; C. SMrTH, op. cit., pág. 41.

33 L. ChaloN, A propos..., págs. 220-229; L'histoire..., págs. 30-31, 165.

34 L. Chalon, L'histoire..., págs. 145-147.

35 Cfr. Cristiano Grottanelli, Giuseppe nel pozzo I. Un antico tema mitico in Gen. 37: 12-24 e in RV I 105 en «Oriens Antiquus», XVII, 1978, págs. 107-122.

36 Biblia Sacra, Vulgatae editionis, Sixti V Pont. Max. iussu recognita et Clementi VIII auctoritate edita, Marietti, Roma, 1959, Gen. 37, 19-36.

37 Les Oeuvres de Adenet le Roi, por A. Henry, Bruselas, Paris, 1963, tomo cuarto.

38 Florence de Rome, Chanson d'aventure du premier quart du XIIIe siecle publiée par A. Wallensköld, tome I et II, Firmin-Didot (SAFT), Paris, 1907-1909. En esta obra, de la que tenemos una versión española desde principios del siglo xrv, con el título El cuento muy fermoso del emperador Otas de Roma y de la infante Florençia su fija e del buen cavallero Esmere, la heroina, durante una ausencia del marido, que está en guerra, es insidiada por su cunado, Milón. Le encarcela, pero, cuando Esmere va a regresar, le libera y juntos salen al encuentro del rey. Durante este viaje Milón, que no acepta el rechazo de Florence y que quiere vengarse de ella, la asalta y, como no logra su proyecto, por la intercesión de una joya mágica de la mujer, la azota y la deja medio muerta en una selva, de donde, después, la salvarán. 
y el justo castigo de los culpables. Por lo que atañe a las semejanzas literarias, no creo se pueda aceptar completamente un origen de las Chansons de gestes francesas. Por ejemplo, las analogías entre el episodio del Poema de mío Cid, que tiene como protagonistas a doña Elvira y a doña Sol, y el de la Florence de Rome (canción y novela ${ }^{39}$, fechadas en el primer cuarto del siglo XIII pero derivadas de un original más antiguo), son muchas y pienso - con C. Smith como con R. M. Walker ${ }^{40-}$ que no se puedan subestimar, lo mismo que el episodio que se refiere a la vista de Valencia y de sus alrededores, en el cual vemos como protagonistas a doña Jimena, que tendría un antecedente en la vista que de París y sus cercanías realiza Blanchifleur en la Berte aus grans piés ${ }^{41}$. Sin embargo, sigo pensando que se trata de cultura literaria re-elaborada de manera original por el autor y no de una banal transposición de unos episodios de un idioma al otro (dado que los modelos originales arquetípicos de cada género son pocos y que, en tiempos particulares, las ideas parecen difundirse contemporáneamente en varios países). Que el autor del Cid conoció canciones francesas es cosa que no puede sorprender al que recuerde cómo en este tiempo fueron frecuentes las relaciones mercantiles y culturales entre Francia y España, y que Leonor, la hija de

39 Chanson, cfr. n. 38; tome II, págs. 1-263, v. 6410; Román, tome I, págs. 131-280, v. 4562.

40 C. SMITH, op. cit., págs. 127-140; R. M. WALKER, op. cit., págs. 336-337.

41 PMC, vv. 1610-1618:

Adeliñó mio Cid con ellas al alcáçer,

allá las subie en más alto logar.

Ojos vellidos catan a todas partes,

miran Valençia cómmo yace la çibdad,

e del otra parte a ojo han el mar,

miran la huerta, espessa es e grand,

e todas las otras cosas que eran de solaz;

alçan las manos pora Dios rogar

desta ganançia cómmo es buena e grand.

Berte aus grans piés, vv. 1962-1972:

La dame ert a Montmartre, s'esgarda la valee,

Vit la cit de Paris, qui est longue et lee,

Mainte tour, mainte sale et mainte cheminee;

Vit Montleheri la grand tour quarnelee;

La riviere de Saine vit, qui molt estoit lee,

Et d'una part et d'autre mainte vigne plantee;

Vit Pontoise et Poissi et Meullent en l'estree,

Marli, Montmorenci et Conflans en la pree,

Dantmartin en Goiele, qui molt ert bien fermee,

Et mainte autre grant vile que je n'ai pas nommee.

Molt li plot li pays et toute la contree. 
aquella maravillosa mecenas que fue Alienor d'Aquitaine, reinó en España como mujer de Alfonso VIII.

No acepto la re-elaboración de la Florence por el autor del Cid, ya sea por los motivos, diferentes, que empujan a los dos hermanos (suposición, jactancia e inoportuna indignación) y a Milón (deseo de poseer a Florence), ya sea por el tipo de suplicio infligido a las jóvenes, que es semejante, pero que a menudo se encuentra en la literatura novelesca. En literatura, ya desde la más antigua, no faltan episodios de mujeres ultrajadas por diferentes causas: Calliroe ${ }^{42}$, perseguida por la envidia de sus pretendientes rechazados ${ }^{43}$, es azotada y dejada como muerta por su marido ${ }^{44}$; Anzia ${ }^{45}$, primero parece morir ${ }^{46}$, luego resucita ${ }^{47}$, pero es condenada a muerte ${ }^{48}$ y por fin la pegan los celos ${ }^{49}$; en la novela de Aquiles Tacio, conocida también como Leucippe e Clitofonte ${ }^{50}$, la mujer

42 Chariton, Le Roman de Chairéas et Callirhoé, texte établi et traduit par Georges Molinié, Les Belles Lettres, Paris, 1979.

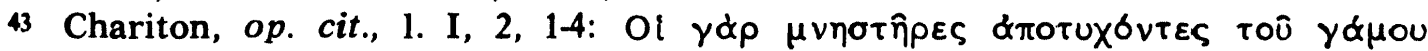

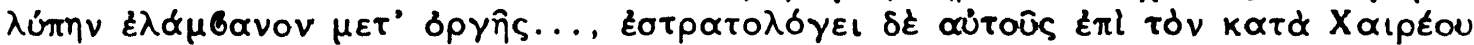

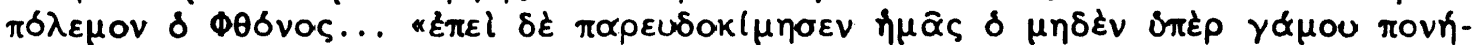

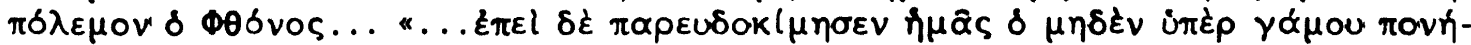

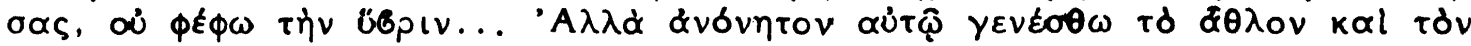

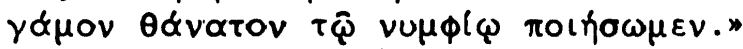

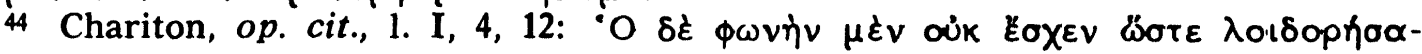

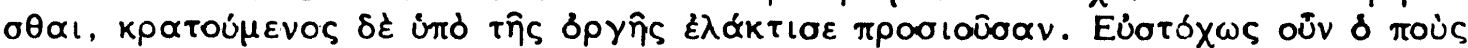

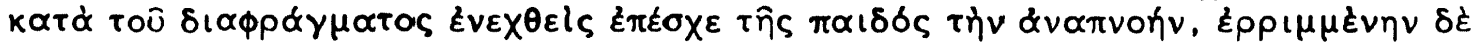

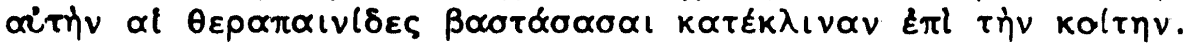

45 Xénophon d'Ephèse, Les Ephesiaques ou Le Roman d'Habrocomès et d'Anthia, texte établi et traduit par Georges Dalmeyda, Les Belles Lettres, Paris, 1926.

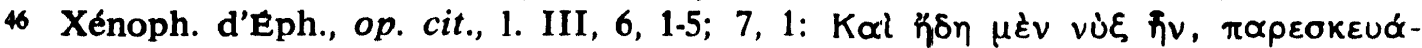

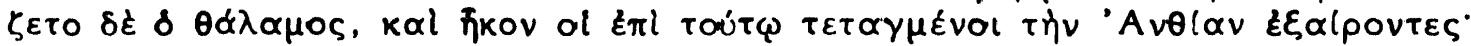

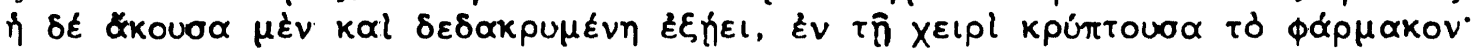

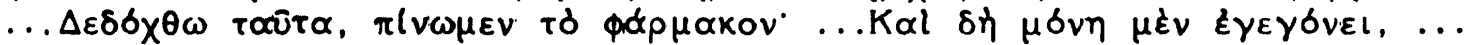

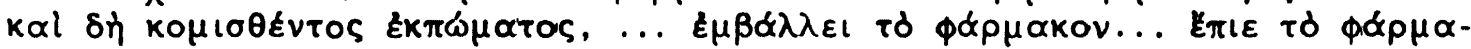

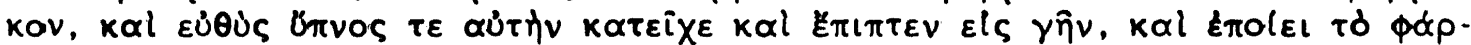

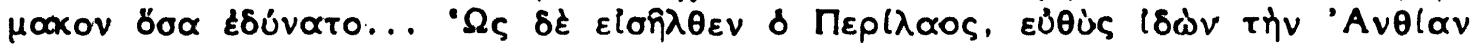

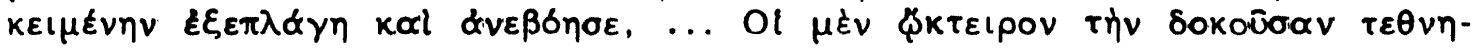
KÉval, ...

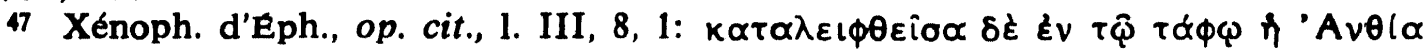

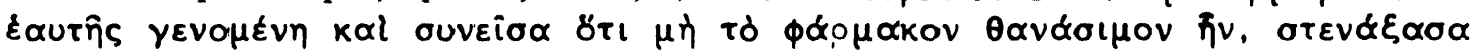
$k \propto l \delta \alpha \kappa \rho u ́ \sigma \alpha \sigma \alpha$.

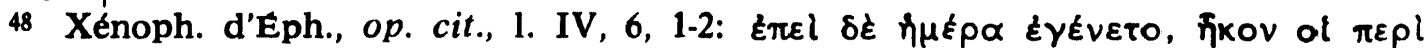

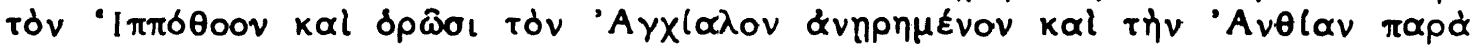

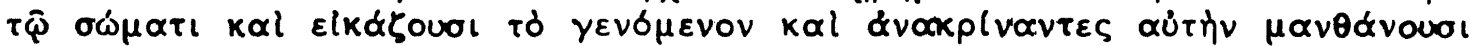

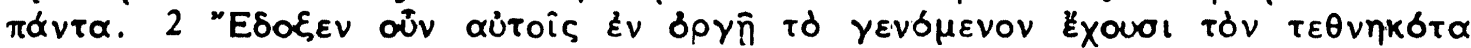

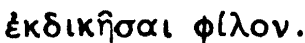

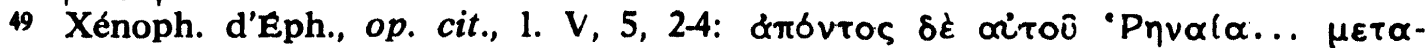

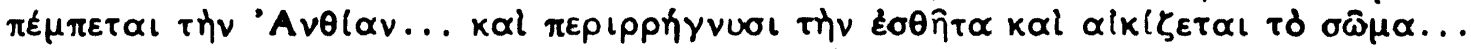

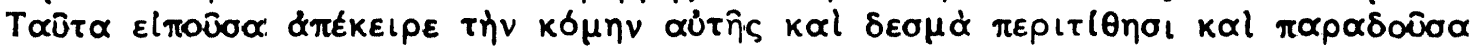

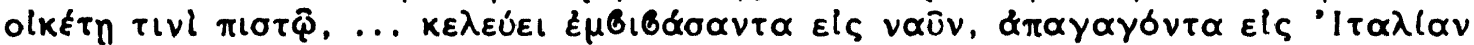

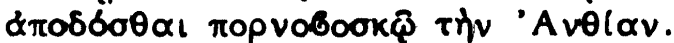

so Achilles Tatius. - with an english translation by S. Gaselee, Heinemam, London, 1947. 
muere y resucita dos veces ${ }^{51}$; en la novela de Apuleyo, las Metamorphosis ${ }^{52}$, en el trozo del cuento de 'Amor y Psique' 53, la muchacha, atormentada por el recelo de sus hermanas ${ }^{54}$, empujada a descubrir la identidad del misterioso esposo ${ }^{55}$, atrae sobre sí una cadena sin fin de adversidades

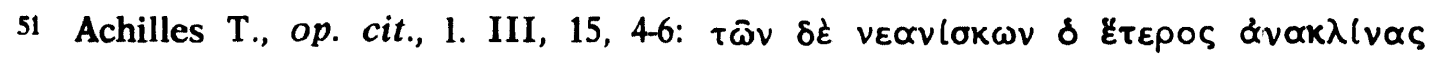

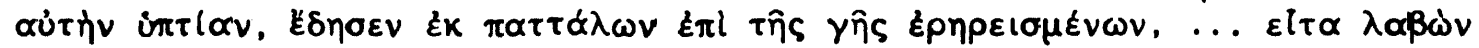

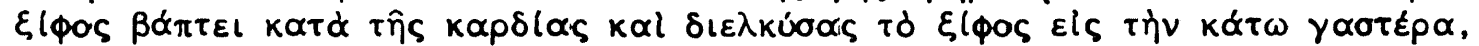
pं

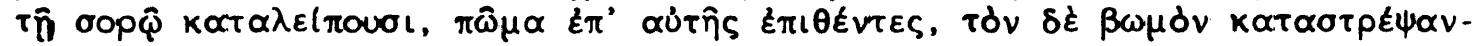

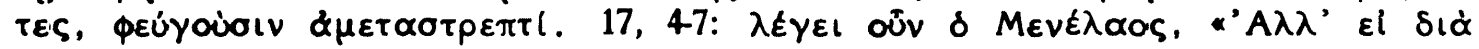

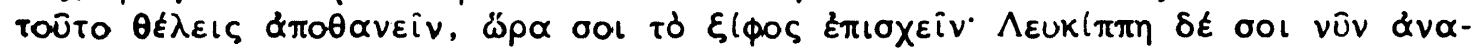

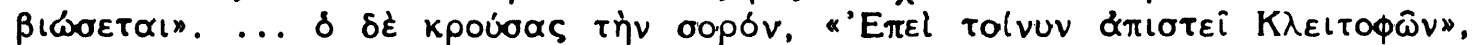

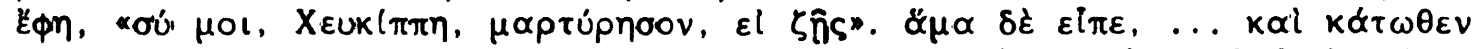

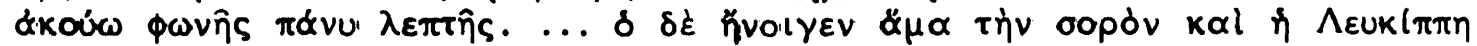

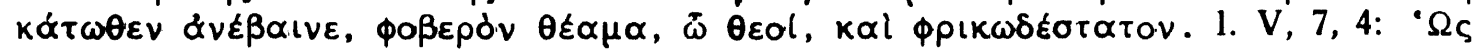

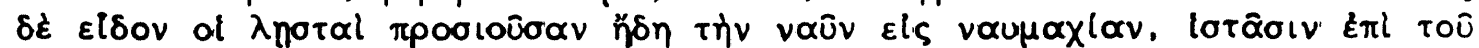

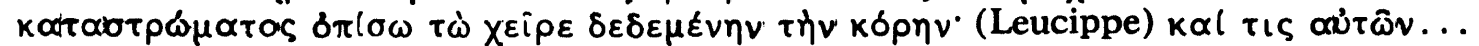

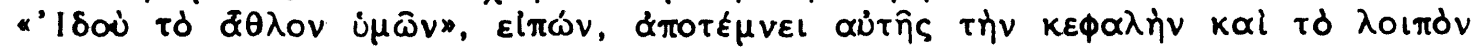

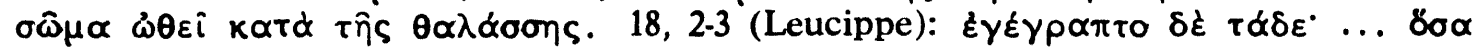

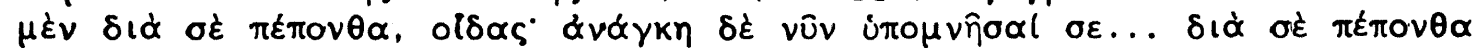

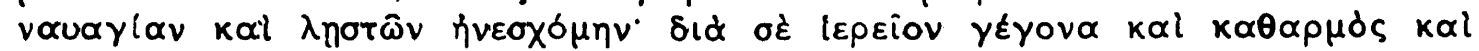

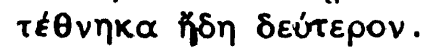

52 APuléE, Les Métamorphoses, texte établi par D. S. Robertson et traduit par Paul Vallette, Les Belles Lettres, Paris, 1940, 3 tomes.

53 APUlke, op. cit., tome 2me, págs. 32-93.

54 APULÉE, op. cit., tome 2me, 1. V, 9: Quo protenus perpetrato sorores egregiae domum redeuntes... multa secum mutuis perstrepebant... «Quodsi maritum etiam tam formosum tenet ut affirmat, nulla nunc in orbe toto felicior vivit... At ego misera primum patre meo seniorem maritum sortita sum, dein cucurbita calviorem et quovis puero pusilliorem, cunctam domum seris et catenis obditam custodientem». 10: Suscipit alia: "ego vero maritum articulari etiam morbo complicatum curvatumque ac per hoc rarissimo venerem meam recolentem sustineo...: enimvero ego nequeo sustinere ulterius tam beatam fortunam allapsam indignae... Nec sum mulier nec omnino spiro, nisi eam pessum de tantis opibus deiecero".

55 APULÉ, op. cit., t. 2, 1. V, 15: Nec tamen scelestarum feminarum nequitia... conquievit, sed ad destinatam fraudium pedicam sermonem conferentes dissimulanter occipiunt sciscitari qualis ei maritus et unde natalium secta cuia proveniret. 17: «...nos autem, quae pervigili cura rebus tuis excubamus, cladibus tuis misere cruciamur. Pro vero namque comperimus nec te, ...celare possumus immanem colubrum multinodis voluminibus serpentem, veneno noxio colla sanguinantem hiantemque ingluvie profunda, tecum noctibus latenter adquiescere. Nunc recordare sortis Pythicae, quae te trucis bestiae nuptiis destinatam esse clamavit... 18: Nec diu blandis alimoniarum obsequiis te saginaturum omnes adfirmant, sed cum primum praegnationem tuam plenus maturaverit uterus, opimiore fructu praeditam devoraturum... 20: viam quae sola deducit iter ad salutem diu diuque cogitatam monstrabimus tibi. Novaculam praeacutam... absconde, lucernamque concinnem... subde aliquo claudentis aululae tegmine... postquam sulcatum trahens gressum cubile solitum conscenderit iamque porrectus et exordio somni prementis implicitus altum soporem flare coeperit... caecae tenebrae custodia liberata lucerna... opportunitatem mutuare, et... noxii serpentis nodum cervicis et capitis abscide. Nec nostrum tibi deerit subsidium». 22: Tunc Psyche... fati tamen saevitia subministrante viribus roboratur, et prolata lucerna et adrepta novacula sexum audacia mutatur. Sed cum 
y el feroz desdén de la suegra, Venus ${ }^{56}$, que la atormentará ${ }^{57}$ hasta el feliz desenlace del episodio ${ }^{58}$. En el mundo medieval de las Chansons francesas las mujeres algunas veces son atormentadas, casi siempre sólo moralmente, pero, tal vez, también azotadas, como por ejemplo en el Perceval ${ }^{59}$. Si acaso, al contrario, se les reprocha preferir un hombre

primum luminis oblatione tori secreta claruerunt, videt omnium ferarum mitissimam dulcissimamque bestiam, ipsum illum Cupidinem formonsum deum formonse cubamtem.

56 APUl.ÉE, op. cit., t. 2, 1. VI, 9: Quam ubi primum inductam oblatamque sibi conspexit Venus, latissimum cachinnum extollit et...: "Tandem» inquit "dignata es socrum tuam salutare? An potius maritum... intervisere venisti? Sed esto secura, iam enim excipiam te ut bonam nurum condecet"; et: "Ubi sunt» inquit «Sollicitudo atque Tristiaties ancillae meae?" Quibus intro vocatis torquendam tradidit eam... Tunc rursus sublato risu Venus: «Et ecce» inquit «nobis turgidi ventris sui lenocinio commovet miserationem, unde me praeclara subole aviam beatam scilicet faciat... et vilis ancillae filius nepos Veneris audiet...; impares enim nuptiae et praeterea in villa sine testibus et patre non consentiente factae legitimae non possunt videri ac per hoc spurius iste nascetur, si tamen partum omnino perferre te patiemur».

57 APULÉ, op. cit., t. 2, 1. VI, 10: His editis involat eam vestem plurifariam diloricat capilloque discisso et capite conquassato graviter affligit, et... sic ad illam: "Videris enim mihi tam deformis ancilla nullo alio sed tantum sedulo ministerio amatores tuos promereri: iam ergo et ipsam frugem tuam periclitabor...». 11: Sed Aurora commudum inequitante vocatae Psychae Venus inflit talia: «Videsne illud nemus...? Oves ibi nitentis auri vero decore florentes incustodito pastu vagantur. Inde de coma pretiosi velleris floccum mihi confestim... afferas censeo». 13: «Videsne insistentem celsissimae illi rupi montis arduis verticem, de quo fontis atri fuscae defluunt undae... et Stygias inrigant paludes et rauca Cocyti fluenta nutriunt? Indidem mihi de summi fontis penita scaturrigine rorem rigentem hauritum ista confestim defer urnula». 16: «Iam tu quidem magna videris quaedam mihi et alta prorsus malefica, quae talibus praeceptis meis obtemperasti naviter. Sed adhuc istud, mea pupula, ministrare debebis. Sume istam pyxidem... protinus usque ad inferos et ipsius Orci ferales penates te derige. Tunc conferens pyxiden Proserpinae: 'Petit de te Venus... modicum de tua mittas ei formonsitate...' Sed haud immaturius redito, quia me necesse est indidem delitam theatrum deorum frequentarex.

58 Después todas estas angustias finalmente Júpiter, delante de los dios, dice, 1. VI, 23: "Sume Psyche, et immortalis esto, nec umquam digredietur a tuo nexu Cupido sed istae vobis erunt perpetuae nuptiae».

59 Christian von Troyes, Der Percevalroman (Li Contes del Gral), herausgegeben von Alfons Hilka, Niemeyer, Halle (Saale), 1932, págs. 45-46, vv. 1033-1052:

A une pucele venue

Bele et jante, si la salue,

Et ele lui et si li rist

Et an riant itant li dist:

«Vaslez, se tu viz par aage,

Je pans et croi an mon corage

Qu'an trestot le monde n'avra,

N'il n'iert, ne l'an ne l'i savra

Nul meillor chevalier de toi:
Einsi le pans et cuit et croi .

Et la pucele n'avoit ris,

Passez avoit anz plus de sis,

Et ce dist ele si an haut

Que tuit l'oïrent. Et Keus saut,

Cui la parole enuia mout,

Si li dona cop si estout

De la paume an la face tandre

Qu'il la fist a la terre estandre. 
menos amable, a un amante, cortés y fiel, porque esto les da una disculpa al consentimiento, que, en realidad, ya desean, pero que, por decoro formal, no quieren abiertamente dar ${ }^{60}$. El concepto no es original, porque Aquiles Tacio, perfectamente coherente con casi toda la literatura griega, en el 1. I, 10 de su novela ${ }^{61}$ dice, a propósito de las

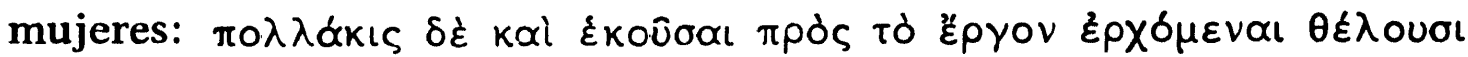

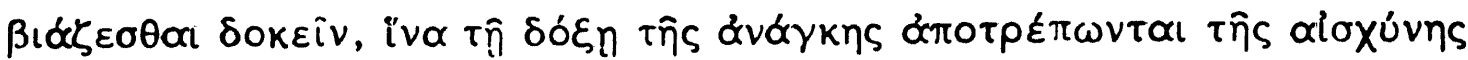
Toे हैkoúolov.

En el mundo oriental de Le mille e una notte 62 aparecen dos cuentos, Peripezie di una pia donna israelita y Una devota salvata dal naufragio ${ }^{63}$, en los cuales las heroínas, después de varias penas, vencen a sus perseguidores. En el ámbito de obras destinadas a un auditorio menos rebuscado, como en los Fabliaux ${ }^{64}$, encontramos le Du vilain mire ${ }^{65}$ y $L a$ veuve ${ }^{66}$ donde las mujeres son golpeadas.

pág. 167, vv. 3715-3739:

Et une pucele ot desus;

Einz tant cheitive ne vit nús.

Neporquant bele et jante fust

Assez, unsetbieneli esteüst;

Mes si malemant li estoit

Qu'an la robe qu'ele vestoit

N'avoit plainne paume de sain,

Einz li sailloient fors del sain

Les memeles par les rotures.

A neuz et a grosses costures

De leus an leus ert atachiee,

Et sa charz paroit dehachiee
Ausi con s'il fust fet de jarse;

Que ele l'ot crevee et arse

De chaut, de halle et de la gelee.

Desliiee et desafublee

Estoit, si li paroit la face

$\mathrm{Ou}$ il ot mainte leide trace;

Que ses lermes sanz prandre fin

I avoient fet maint train

Et jusqu'au sain li avaloient

Et par desor la robe aloient

Jusque sor les genouz colant.

Assez pooit avoir dolant

Le cuer qui tant meseise avoit.

oo Simonetta Bianchini, Due brevi romanzi di Chretien de Troyes?, en «C. N.», XXXIII, 1973, pág. 62, evidencia muy bien este comportamiento con las palabras mismas de Chretien:

Qui beise fame, et plus n'i fet,

Des qu'il sont seul a seul andui,

Dons cuit je qu'il remaint au lui.

Fame qui sa boche abandone

Le soreplus de legier done,

S'est qui a certes $i$ antande;

Et bien soit qu'ele se desfande,

Si set an bien sanz nul redot
Que fame viaut vaintre par tot

Fors qu'an cele meslee sole:

Quant ele tient home a la gole

Et l'esgratine et mort et tue,

Si voldroit ele estre vaincue,

Si se desfant et si li tarde.

Tant est de l'otroiier coarde,

Einz viaut qu'an a force li face.

(Chretien von Troves, ob. cit., pág. 174, vv. 3860-3875).

61 AQuiles Tacio, cfr. n. 50.

62 Le mille e una notte, Einaudi (Gli Struzzi, 35), Torino, 1972.

63 Le mille e una notte, ed. cit., págs. 553 y 558.

64 Fabliaux, Racconti francesi medievali, Einaudi (I Millenni), Torino, 1980.

65 Fabliaux, pág. 174, vv. 77-84:

Et quant la table fu ostee, de la paume q'ot grant et lee, 
Exactamente en los Fabliaux, así como en el Perceval, emerge de nuevo un acento bastante fuerte de misoginia que, descubierto en las novelas griegas (ausente en los dos cuentos de Le mille e una notte, de cultura no griega), siempre aparecerá más fuertemente en la literatura europea posterior, pero que me parece ausente en el Cid, donde los personajes femeninos, aunque no se muestran con la misma fuerza de los protagonistas masculinos, sin embargo, son delineados con cuidado casi afectuoso y sin que nunca decaigan en sus papeles. La cultura medieval ve un cierto número de mujeres artistas y mecenas (y estoy de acuerdo perfectamente con lo que dice Rita Lejeune en su ensayo ${ }^{67}$ sobre las mujeres que, con la marcha de los Cruzados, adquieren «une puissance politique et un pouvoir économique qu'elles n'avaient pas encore connu»), pero es necesario decir que siempre se trata de personajes que sobresalen gracias a sus condiciones sociales privilegiadas (Alienor de Aquitania, María de Francia, etc.) y que por lo tanto no se pueden considerar como seres del mundo común; la falta de cultura de las otras se sitúa en el mismo nivel y, en muchos casos, mucho más bajo que el grado de culturalización masculina.

En la Florence de Rome, de la cual algunos quieren ver reminiscencias en el Cid (y puede ser que eso no esté muy lejos de la verdad), la

fiert si sa fame lez la face, que des doiz i parut la trace. Puis l'a prise par les cheveus li vilains, qui mout estoit feus, si l'a batue tout ausi con s'ele l'eüst deservi.

Fabliaux, págs. 266-268, vv. 510-522:

Il ne dist mie: Dex vos saut, ains le saisist par les lubars, se li done des esclabars.

Tant li promet et tant li done que tot ce dit li gueredone; puis li resaut sor le jovente, tant le fiert del puing et avente qu'il en est sullens et lassés. Qant il l'en a donet assés, li dame ens en sa canbre muce, tot sans capel et sans aumuce. Tant a soferte la mellee que la teste en a conmellee.

67 Rita Lejeune, L'image de la femme dans la littérature, en «Cahiers de Civilisation médiéval», X-XII siècle, Poitiers, Centre d'études supérieurs de civilisation médiéval, XX année, n. 2-3, 1977, págs. 209-217. 
protagonista sufre una injuria semejante a la de las hijas del Cid ${ }^{68}$. Pero hay en los dos cuentos un particular muy diferente: en la Florence el perseguidor, Milón, amenaza a la mujer, que llora y se desespera, con matarla, si no se somete a su voluntad y no acepta sus ofertas, con un golpe de espuela ${ }^{69}$; después la azota con un haz de espinas y la deja,

68 PMC, vv. 2720-2748:

Allí les tuellen los mantos e los pelliçones, páranlas en cuerpos y en camisas y en çiclatones. Espuelas tienen calçadas los malos traydores, en mano prenden las çinchas fuertes e duradores.

Lo que ruegan las dueñas non les ha ningún pro. Essora les conpieçan a dar ifantes de Carrión; con las çinchas corredizas májanlas tan sin sabor; con las espuelas agudas, don ellas an mal sabor, ronpien las camisas e las carnes a ellas amas a dos; linpia salie la sangre sobre los çiclatones. Ya lo sienten ellas en los sos coraçones.

Tanto las majaron que sin cosimente son; sangrientas en las camisas e todos los çiclatones. Canssados son de ferir ellos amos a dos. Ensayandos amos quál dará mejores colpes. Ya no pueden fablar don Elvira e doña Sol, por muertas las dexaron en el robredo de Corpes.

69 Florence

- "Dame», ce respont Milles, "vos parlez de folie.

Gardez qu'il n'i ait mot ne parolle tentie,

Gemès ne la verrez en tote vostre vie;

Et, se vos fetes noise, par Deu, le fil Marie,

Coperai vos la teste a m'espee forbie».

(vv. 3696-3700)

Et Milles point après, si a trete l'espee, Si l'en done dou plat une si grant colee Que Florence la belle est chaete pamee.

(vv. 3716-3718)

- «Dame», ce respont Milles, «trop iestes emparlee.

De vostre cors ferai quand qu'a mon cuer agree,

Car c'est la riens ou siecle que plus ai desirreex.

(vv. 3733-3735)

- "Certes», dist li traitres, que mout fu irascuz, «Bien me membre de Romme, quant je fu retenuz; Onques ne m'ot mestier de lance ne escuz, Mès par vos fui a terre ledement abatus. Et je cuit que briement vos esters randuz; Et, se vos festes noise, par Deu que fait vertuz, $\mathrm{Ou}$ cors vos embatrai mes esperons agus».

(vv. 3764-3770) 
colgada por el pelo del tronco de un árbol, medio muerta ${ }^{70}$. En el Romancero, en los Romances del Cid números 26 y $27^{71}$, se encuentran casi los mismos particulares:

De sus caballos descienden, (los Infantes)

las riendas les han quitado;

sus mujeres que lo ven

muy gran llanto han levantado.

Apéanlas de las mulas;

ambas las han desnudado;

70 Florence

Isnellement et tost tret dou fuerre l'espee,

Puis va a une branche, si l'a par mi copee,

Qui fu de leurs en leus par trestot espinee;

Plains ces poins en aporte, s'a Florence cobree,

Si la fiert de son pié, qu'a terre l'a gitee,

Par flans et par coustez l'a tant forment foulee

Que sa blanche char fu trestote ensanglantee

Et la poipre de soie deroute et desiree.

(vv. 4092-4099)

- "Certes», ce respont Milles, «trop iestes enparlee;

De vostre cors ferai quan qu'a mon cuer agree.

Desfetes les charaudes sens nulle demoree».

(vv. 4102-4104)

Quant or ot li traïtres que Florence parla,

Si grant maltalant ot par poi ne forcena.

Il la prist par les tresces, soz l'arbre la mena,

Le grele de ses manches sor les mains li cola;

Tant doloreusement li leres les lia

Que la tige de l'arbre par derriere enbraça.

Une branche $i$ ot grose que vers terre enclina,

Par les tresces l'i pent, tant forment la pena

C'onques pié qu'elle eust a terre ne tocha

Fors seul l'ortoel devant, ou elle s'apuia.

(vv. 4108-4117)

Quant Milles, li traïtres, a Florence entendue,

Si grant matalant ot tot le cors li tresue.

Lors ra prises les verges, si la ra tant batue

Sa blanche char en fu sanglante et derompue;

Le sanc vermeil en chiet desus l'erbe menue.

(vv. 41244128)

Quant Milles l'entendi, a poi que ne se tue.

Florence pent a l'arbre tant doloreusement

Que riens n'en toche a terre fors sol l'ortoel devant;

A l'arbre fu loiee mout par estroitement.

(vv. 4140-4143)

71 Ramón Menéndez Pidal, Flor Nueva de Romances Viejos, Espasa-Calpe, Madrid, 1969, págs. 186 y 187. 
cada uno azota la suya,
con riendas de su caballo;
danles muchas espoladas,
en sangre las han bañado;
con palabras injuriosas,
mucho las han denostado.

Rom. 26, vv. 41-52.

Rom. 27 , vv. 1-8.

La enormidad del hecho es doble: los golpes a una mujer de alta condición social no son, en fin, cosa común en el mundo de las Chansons y sobre todo un verdadero caballero no deshonraría nunca lo que, con la cadena de oro, es uno de los símbolos típicos de su estado, con un acto tan denigrante. Walker, en su ensayo citado (pág. 344), dice: «By doing this, of course, the Infantes degrade the most honoured symbols of knighthood".

Resulta por eso aún más patente la inferioridad moral de los Infantes de Carrión y su mezquinidad, frente a la grandeza de ánimo y la profundidad de los afectos del Cid, que parece no tanto un ser perfecto, sino un hombre provisto de las más deseables cualidades; sujeto, como todos, a dudas y a cóleras, pero firme en la defensa de sus afectos, bien se trate de proteger a amigos o a su familia. No es un caballero andante, como muy bien aclara Francisco López Estrada ${ }^{22}$ : "Las aventuras del héroe no son deportivas, en el sentido noble de la palabra, sino que están al servicio de la comunidad; y el pueblo las recibe como un ejemplario de virtudes caballerescas, guerreras y políticas, con lo que el Poema participa también del sentido didáctico, tan peculiar de la literatura del Medievo".

Los ejemplos literarios semejantes al episodio de la Afrenta de Corpes hasta ahora aportados, sobre todo por lo que atañe a los griegos, no constituyen prueba, visto que no podemos demostrar, documentos en mano, sus transcripciones y eventuales re-elaboraciones hechas en España, dado que, después de las invasiones bárbaras y durante largo

72 F. LÓPEZ Estrada, op. cit., pág. LXXVII. 
tiempo, el griego desaparece de la cultura europea para reaparecer después de la caída de Constantinopla. Pero, en compensación, tenemos otro filón narrativo, más reciente, que seguramente ha llegado hasta los extremos del mundo occidental de la época: las historias de las Vidas de los Santos, nacidas y provenientes del Medio-Oriente junto con los Itineraria y las Peregrinationes.

Son exactamente las vidas de los Santos o unas historias de milagros las que heredan el sentido de lo maravilloso y de lo excepcional de las novelas. Más bien, según Wallensköld ${ }^{73}$ y muchos otros autores, toda la narrativa tiene origen en la India y sobre ella se habría insertado también la novela griega y sus derivados.

En ambos casos, el conocimiento de cuentos antiguos puede probar el alto nivel de estudio del autor del Cid que, casi seguramente, no podía ser un juglar, si bien es verdad que los cuentos de las vidas de los Santos son conocidos en todo el mundo, porque constituían el bastidor de muchas "representaciones sagradas».

Por otra parte, no se puede olvidar que España ha sido, a partir de la dominación árabe y de las varias cortes derivadas, sobre todo con el reino de Granada y con los de Taifas, un punto de difusión de cultura musulmana en Europa, que se ha sobrepuesto y enlazado con cuanto quedaba de la cultura clásica todavía viva gracias a los monasterios, desde siempre guardianes y divulgadores de códices antiguos y creadores, en este tiempo, de algunas de las raíces de una nueva culturalización. A todo esto tenemos que añadir los intercambios mercantiles y literarios favorecidos por el reino de Aragón, los conocimientos aprendidos y difundidos por los peregrinos que de todas partes del mundo iban y venían entre Santiago de Compostela, Roma y Jerusalén, lo que habían asimilado de la cultura árabe o judía en sus largas estancias en Tierra Santa los Cruzados (aunque la mayoría de ellos tuviese un nivel cultural bastante escaso como casi todos los hombres de armas) y el hecho de que existían en España, ya desde hacía mucho tiempo, "colonias» judías que conservaban una cultura apoyada en el Antiguo Testamento y que a menudo tenían un elevado nivel cultural, como muestran sus poetas. Por todos estos motivos, España fue como un crisol que amalgamó lo antiguo y lo contemporáneo y no hay que maravillarse si la primera obra literaria castellana que conservamos nos muestra, de vez en cuando, una u otra faceta, sin que por eso necesariamente se tenga que hablar de préstamos culturales, si con estas palabras se quiere indicar una falta de

73 WallensköLd, La Florence de Rome, Introduction, cap. VII, págs. 105-130. ANTONIO RUIZ DE ElviRA, El valor de la novela antigua a la luz de la ciencia de la literatura, en «Emerita», Madrid, XXI, 1953, págs. 64-110. 
originalidad y no la huella del mundo que la rodeaba. España, como otras naciones, recogió lo que ya tenía y a la luz de los nuevos conocimientos y modelos, produjo con el Poema de mío Cid una obra completamente española y original, aunque naturalmente en ella se pueda encontrar algo común al mundo de la novela caballeresca de toda Europa y peculiaridades que hunden sus raíces en la más antigua cultura. Lo que estoy convencida de que prueba, una vez más, el alto nivel cultural de su autor.

MaRINa CONTI 